\title{
Putting the context into learning
}

\author{
RICHARD EDWARDS, \\ University of Stirling, UK \\ KATE MILLER, \\ University of Dundee, UK
}

\begin{abstract}
The article explores the conceptualisation of learning and context from a number of perspectives and some of the theoretical and methodological issues raised when context is no longer considered a container, but as a relational effect. It provides an introduction for the articles that follow, insofar as they take up lines of flight from the issues raised. Central to the article are the questions of what makes something specifically a learning context and what different ways of conceiving the relationship between learning and context might be and with what implications.
\end{abstract}

\begin{abstract}
Research on everyday practices typically focuses on the activities of persons acting, although there is agreement that such phenomena cannot be analyzed in isolation from the socially material world of that activity. But less attention has been given to the difficult task of conceptualizing relations between persons acting and the social world. Nor has there been sufficient attention to rethinking the 'social world of activity' in relational terms. Together, these constitute the problem of context. (Lave 1996: 5, emphasis in original)
\end{abstract}

\section{Introduction}

This special edition of Pedagogy, Culture and Society arises from a series of seminars (http://crll.gcal.ac.uk/tlrp.php) that took place in the UK in 2005 and 2006, which aimed to explore pedagogically, conceptually and methodologically the relationship between learning and context and address the question of what specifically constitutes a learning context. The seminar series arose from work undertaken within the Teaching and Learning Research Programme (www.tlrp.org). For a number of years this programme has funded projects focusing on teaching and learning in different domains - schools, colleges, universities, workplaces, community. From individual projects a number of cross-cutting themes emerged for more explicit exploration. The question of learning and context was one such theme. These are not new questions. In their edited collection, Chaiklin and Lave (1996) suggest that all social practices are contextualized and involve learning, but how those practices are conceptualized is more contentious. Central to many contemporary discussions of learning, drawing upon situated learning theory, activity theory, complexity theory and actor-network theory, are questions about how we frame an understanding of learning and context.

The articles included in this edition of the journal are a selection of those which were presented at the various seminars in the series. Authors have updated and 
extended their original papers in the light of discussion and feedback and the articles have been subject to the normal reviewing process for this journal. This article provides a survey of some of the existing literature and some of the issues it raises as a way of framing what follows.

\section{Background}

Questions of context are brought into particular stark relief by developments promoted through a discourse of lifelong learning. If learning is lifelong and lifewide, what specifically then is a learning context? Are living and learning collapsed into each other? Under the sign of lifelong learning and following work on situated learning (e.g. Lave and Wenger 1991), a great deal of attention is being given to those domains outwith educational institutions and other structured learning opportunities wherein people are held to learn. The workplace, the home and the community are all held to be domains of learning, within which there are specific sites. In this sense, there are learning contexts distributed across the social order and embedded in social practices to such an extent that the social order is itself already a learning context, and potentially learning becomes an undifferentiated practice. That this is the case has become perhaps most apparent in the development of distributed, blended and online learning through the use of information and communication technologies (ICTs) and the use of the Internet as a site and resource for learning and its associated network metaphors.

Insofar as we expand our concept of learning to embrace apparently all domains of life, we might be said to start to lose the conceptual basis for talking specifically of a learning context. This raises important questions.

- What is specific to a learning context which is not to be found in other contexts?

- What characterizes a specifically learning context?

- What is the relationship between learning and context?

- Who names these contexts as learning contexts?

The latter is important insofar as the discourses of educators and researchers are not necessarily shared by those who are engaging in practices within the domains identified as contexts of learning. Thus, for instance, doing family history may be considered a leisure activity by those who are engaging in it, when for many educators, this would be considered a form of learning. The meaning and significance of social practices can therefore vary. Insofar as people do not identify themselves as learning in different domains, they may not draw upon the resources and relationships available to them for learning in other domains. Here it is a question of what can be ascribed as learning by whom, rather than discovered to be learning.

Insofar as learning is identified as taking place in a range of domains and the learners themselves move in and between these domains, then we raise issues of transfer, the movement of learning and identity from one activity to another. This may be from task to task within a single domain or between domains, signifying different distances between contexts. However, even here we have to cautious, as that notion of learning being transferred from one activity to another already 
assumes a certain view of learning and context, where learning is taken from one box and put in another.

The question then emerges about how we understand a learning context, when the learning is not bounded by a specific set of institutional relationships and structures. Pedagogic approaches may seek to bound the learning and the learner, but there is also the sense in which there is a desire for learning to be mobile, to be for a purpose. This is exemplified, for instance, in the discourses of transferability and transferable skills and those of the recognition of prior experiential learning. In this sense, a context may be considered a bounded container within which the learning takes place or a more fluid and relational set of practices. In the former, there is a sense in which there is closure to contain or structure the learning, which once acquired may, in principle, be poured from one domain container to another. Here

In all commonsense uses of the term, context refers to an empty slot, a container, into which other things are placed. It is the 'con' that contains the 'text', the bowl that contains the soup. As such, it shapes the contours of its contents: it has its effects only at the borders of the phenomenon under analysis... A static sense of context delivers a stable world. (McDermott, quoted in Lave 1996: 22-3)

The relational framings find expression in theories of learning that emphasize activity and draw upon concepts of communities and networks rather than that of context. Here, rather than a thing, context is an outcome of activity or is itself a set of practices - contextualizing rather than context becomes that upon which we focus (Nespor 2003). Practices and learning are not bounded by context but emerge relationally and are polycontextual, i.e. have the potential to be mobilized in a range of domains and sites based upon participation in multiple settings (Tuomi-Grohn, et al. 2003). Learning is a practice of contextualisation rather than simply emerging within a context. To understand context in static or relational terms has effects on how we conceptualize the mobilizing of learning across domains and associated pedagogic practices. To reject the notion of context in favour of that of activity or situated practice is one strategy. To change the understanding of context is another. It is the latter that informs this selection of articles.

\section{Framing contexts}

Once we look beyond the context of conventional sites for education and training, such as schools, colleges and universities, allowing context to be extended into the dimension of relationships between individual learners and variously defined others mediated through a range of social, organizational and technological factors, then the limitations of much conventional pedagogy comes into sharp focus. Pedagogy has for many been defined as contained within the 'spaces of enclosure' of the classroom, the book and the curriculum (Lankshear, et al. 1996). Here learners move from one classroom to another, one curriculum area to another, one institution to another in a linear step-by-step way. Learning is linear and cumulative. Identifying pedagogy in specific sites and domains across the life course may require different conceptual framings where, for instance, there is no teacher as such, or teaching is embedded in texts of various sorts or in the peer support of the team. 
This interest in lifelong learning has expanded the domains in which learning is now a concern for practitioners and the range of people who might be considered to have an educational role. It is not simply educators or teachers who have an educational role, but, for instance, supervisors, mentors, software designers, architects. Learning and pedagogy therefore have become in principle a part of many if not all aspects of social life. At least potentially, the whole of life becomes pedagogized. This is particularly the case when we take into account the growth of the consumer market in learning opportunities (Field 1996) and the structured, if distributed, opportunities and self-structuring practices provided by the Internet and other technologies (Lea and Nicoll 2002). The growth of e-learning and borderless education (Cunningham, et al. 1997) raises significant questions regarding the relationships it can foster across cultures with implications regarding the different cultures of teaching and learning in different contexts and the value placed on different forms of learning. It also raises questions about how the use of computers by learners in one domain - home, workplace - might be drawn into learning within education.

The relationship between learning in different domains is often framed by notions of informal, non-formal and formal learning, and how to mobilize the full resources - e.g. funds of knowledge, literacy practices, experiential learning - of learners within specific sites. From a search of the literature, it is possible to locate a number of areas of debate and conceptual framings relevant to the question of context in the fields of:

- socio-cultural psychology (e.g. Tochon 2000, Edwards 2001),

- applied linguistics (e.g. Barton and Hamilton 1998, Barton et al 2000, Maybin 2000, Russell and Yanez 2003),

- social anthropology (e.g. Lave and Wenger 1991),

- social studies of science (e.g. Bowker and Starr 2000) and

- organizational studies (e.g. Boreham, et al 2002).

These complement and contribute to existing work in education on areas such as

- informal and community-based learning,

- learning in the home,

- workplace learning (e.g. Eraut 2004),

- experiential and vicarious learning e.g. (Mayes, et al 2001),

- vertical and horizontal discourse (e.g. Bernstein 1999), and

- tacit knowledge (e.g. Eraut 2000,).

There is thus a large multi-disciplinary range of resources upon which to pull in order to explore questions of learning and context. Some of this work focuses on domains other than educational institutions e.g. the workplace, some on the relationship between domains e.g. home-school relationships, some on the relationships between learners and other groups, and some on the transferability of learning from one domain to another (e.g. Oates 1992, Harrison 1996 and Eraut 2004). This area is rhizomatic in terms of the conceptual borrowings, entwinings and offshoots, which one can follow and that pop-up all over the place. It is not a 
tidy arena or context of debate, thereby reflexively demonstrating the very complexity it is seeking to illuminate.

What is perhaps significant is that much of the literature on learning is framed within a set of binaries, which separate domains from one another. Thus, broadly within the arena of cultural psychology, there is a distinction made between everyday and formal/scientific learning (see contributions to Murphy and Ivinson 2003). In the realm of applied linguistics, the focus is on vernacular/contextualized and formal/decontextualized literacy practices (Barton and Hamilton 1998) framed within the everyday and educational experiences of learners. In educational research, the debate has become focused around either informal or experiential learning and formal learning.

Each of these binaries identifies that learning is occurring across a range of domains and sites, but that this learning is in some senses situated or contextualized. The range of learning contexts may therefore be extended and what can be identified as learning. However, their very situatedness and pedagogical approaches that assume domains to be discrete - we leave parts of ourselves at the metaphorical door of the classroom - mean that learning from one site is not necessarily realized as a resource in other sites by either teachers or learners. Logically, if learning occurs in particular situations, why should or how can it be relevant to other contexts?

This is the situation to which each of the areas of research addresses itself. There is the identification of a gap and exploration of how that comes to be and how these gaps might be overcome. This is sometimes in order that learners resources can be realized in formal educational sites, but also vice versa, especially where the concern is for the transfer of learning from education to the workplace (TuomiGrohn and Engestrom 2003). Certain aspects of these debates might be perceived as a push-pull effect within research. Within the discourses of education there is tendency to centre the learning context within certain institutional sites, while within the discourses of learning there is a decentring of learning contexts, within which there is an identification of diverse but separate domains e.g. workplace, home, etc.

Learning in different contexts may involve different types of learning, the learning of different somethings, and for different purposes, the value of which might be variable. We might therefore need to question the extent to which, as educational researchers and pedagogic practitioners, we should try to overcome the gaps. Learners themselves might not want to overcome them. It also involves the learning of something particular to each context, even if that something is a form of abstract, generalized knowledge as in parts of the curriculum of education (Lave 1996). Given the contemporary interest in notions of situated learning (Lave and Wenger 1991), there is of course the issue whether that overcoming might be possible at all. The educational rationale for such an approach is often that education is not recognizing or developing the full potential of learners by not mobilizing their full resources in formal sites, or that what is learnt is not relevant to the 'real world'. However, this has a centring logic to it, which tends also to deny conflict and difference in and through learning. It assumes the inherent worthwhileness and benignness of education that denies the very struggles in and around it, where some 
people seek to keep a gap between their lives and what is educationally available. Some might argue that education and pedagogy can and should change to be more inclusive, as though inclusion can overcome all gaps and struggles. However, this is to ignore that inclusions can only occur on the basis of exclusions and the constant play of difference (Edwards, et al. 2001).

A concern is that in starting with these binaries, a whole discourse is produced as a result that sends us down particular pathways, looking at certain things in certain ways. As a result, we may realize only certain pedagogical issues and, perhaps more importantly, we may frame issues in educational terms when more appropriately they should be framed in other ways. With the above theories, there is a tendency for a slippage from framing literacy/learning/knowledge as practices regardless of place to framing them as spatially located practices in particular ways. As a result we end up with discourses and practices about the inside and outside, with metaphors of scaffolding and border crossing, discourses of parity of esteem and practices such as attempts at the accreditation of prior experiential learning and the production of all encompassing credit frameworks.

Similarly, the discussion of informal and formal learning often ignores the informality of learning in educational institutions and the formality of some learning in other organizations (Coffield 2000). Billett (2002) has argued that the informal/formal learning debate is a waste of time and that either people are learning or they are not. Colley, et al. (2003) have argued somewhat differently that attributes (and they are particular about their use of that term) of formality and informality can be found in all learning situations. These suggest that sites of learning are more complex and relational, as to produce the formal there must be a realization of that which is informal and vice versa. In other words, learning contexts are practically and discursively performed and performative. They coemerge with the activities by which they are shaped and vice versa. Indeed Van Oers (1998) suggests dropping the notion of contexts altogether to focus on contextualizing as a set of practices.

In a range of domains concepts of:

- communities of practice (Lave and Wenger 1991, Wenger 1998, Swales 1998),

- networks (Nespor 1994, Fox 2000, Poell, et al. 2000) and

- activity systems (Engestrom et al 1998)

have come to the fore to help frame our understanding of pedagogy and address some of the perceived weaknesses of more conventional cognitive approaches to learning. Situated learning, activity theory and actor-network theory have been drawn upon in different ways by a range of writers to help conceptualize learning that is not confined to educational institutions. Metaphorically and analytically each attempts to frame learning in alternative ways to that of the context as container. There is a paradox in some of this, as the arguments are often that learning is only meaningful within the specific situation or context, but also that the latter is not itself absolutely distinct from other contexts. Thus the significance of notions of practice, activity and polycontextuality. 
This finds expression in some of the different conceptions of authentic learning (Tochon 2000, Stein et al 2004). However, some of these would appear to continue with the binary approach already identified and find alternative ways of bridging the gap. They are of varying degrees of sophistication. Tochon (2000), for instance, discusses an authentic learning zone that brings together:

- $\quad$ situated knowledge - the present moment relationship to knowledge

- $\quad$ biographical knowledge - linked to prior experience, and

- the subject matter to be learnt.

This is more sophisticated than say Stein, et al. (2004: 240) who view authentic learning as when 'activities undertaken by students are like those activities undertaken by “adult” world beyond the learning institution'. In the latter, what marks the authentic is that which is outside the educational institution, mirroring the view that learning in this situation is contextualized rather than the decontextualized learning of institutions. In the former, the authentic is a zone in which the past and present of the learner are mobilized in learning a subject matter; there is no inside and outside. Simulations and boundary zones (Beach 2003, Tuomi-Grohn, et al. 2003) are also formulated as mediators between domains within which pedagogy may seek to mobilize a fuller range of resources for learning than in the formal domain of education.

Conventionally we might focus on what occurs in one context to the exclusion of others. What is suggested here is that this is only an effective pedagogic strategy if we assume context as a container and as a result contain learning. When we start to question that, the interesting pedagogic space is that in-between arena of polycontextual practices, where 'elements from both sides are always present in the boundary zone' (Tuomi-Grohn, et al. 2003: 5). These are not closed spaces but networked and mediated domains, which give raise to alternative framings and metaphors, where context is an effect and not pre-existing the practices that give rise to it.

Here the notion of a boundary object is crucial. The notion of boundary objects was developed in actor-network theory (ANT) (Star 1989), but has also been taken up by Wenger (1998) in his conceptualization of communities of practice. In ANT, 'like the blackboard, a boundary object "sits in the middle" of a group of actors with divergent viewpoints’ (Star 1989: 46). Boundary objects circulate through networks playing different roles in different situations. They are not merely material; boundary objects can be 'stuff and things, tools, artefacts and techniques, and ideas, stories and memories' (Bowker and Star 2000: 298). For Wenger (1998: 107 ) boundary objects work at the edges of communities of practice mediating their external relationships; 'they enable coordination, but they can do so without actually creating a bridge between the perspectives and the meanings of various communities', This requires brokers.

\section{The seminar series as a learning context}

The seminar series from which these articles have been developed was reflexively researched as a learning context in itself and provided an example of how a learning context is an effect of the practices that give rise to it. The focus was on how participants from different backgrounds came together in an exchange of ideas and 
what, how and why that worked and the work that it did. Participants were asked to reflect on their experience of the seminar series as a learning context. Various themes emerged about the physical and virtual nature of interactions; around temporal and spatial factors; about the interactions of animate and inanimate actants; and the multidisciplinary backgrounds of participants. The rich and varied practices that came about as a result of the coming together of a wide range of social, historical, political and educational influences all actively shaped the seminar series as a learning context. The organisers of the series took a leading role in framing the events through inviting the main players and others to participate and providing themes, and structures for the individual seminars. The rest developed as participants came together in various ways and contributed their own experiences and insights.

It was clear that careful planning and consideration of inputs in terms of time, space, texts, technologies, food, people, etc. were all important ingredients in the development of the seminars. In this sense the pedagogy could be identified as the setting up and framing process. The invitation of experienced and less experienced participants and their loosely directed participation in particular small group and plenary sessions played a pedagogic role. In a similar way the engagement of post graduate and early career members of the community in research activities on the seminar series facilitated their participation in the seminars and also played a pedagogic role.

As we are taking a relational view of context, viewing it not as something that preexists practice but rather something that is effected through practices, then the research practices that constituted a strand in the overall design of the seminar series are also implicated in the forming of that context. The complex way in which all these ingredients interacted and evolved in favour of certain ideas and concepts and to the detriment of others and how these developments are taken forward by participants in their future lives is an ongoing process which continues to unravel.

\section{There are more questions than answers}

We cannot begin to fully embrace the conceptual sophistication of all the positions upon which we have drawn above. Some may consider them caricatures, straw persons upon which to build a discussion. The question of context is large and many debates in different domains are relevant. In the domains of research and practice therefore, there are significant issues to be addressed and tensions in approaches to practice and descriptions and explanation of pedagogy. How such framings constitute a learning context and their implications for learning and teaching across the life course requires closer attention therefore. This raises important questions:

- How do we engage the full resources of learners for learning? If people are learning in diverse ways and settings, they already bring important resources to more formal educational provision. How is this best mobilized? This is an issue we find explored in slightly different ways in education, socio-cultural psychology, literacy studies and e-learning, to name a few. What this does is raise issues about how we bound the contexts for learning and whether they can be bound at all. 
- What is the relationship between learning in different sites and domains? If people are learning in different contexts, what is the nature of that learning and how is it transferred, if at all, from one context to another? Is learning in different sites always new learning in some shape or form? How effectively can learners cross contexts in vicarious learning? In what ways can the cultures of learning in everyday life be translated into those of more formal educational practices in the fashioning of learning careers? For educational institutions this raises deep issues of curriculum, values and epistemology and in certain areas the relationship between theory and practice. There are also different units of analysis to be considered in relation to learning across tasks, sites and domains.

- What forms of pedagogy can most effectively mobilise learning across domains and for what purposes? Learning and teaching can now combine virtual and physical sites in ways that challenge existing assumptions about what can be taught and in what ways. Teachers may carry forward unreconstructed pedagogies into contexts where the existence of the virtual challenges how we might best use the face-to-face, as well as the online opportunities. Teaching may also focus on the bounded spaces of the classroom, curriculum and the school at a time when potential learners want more flexible opportunities, with growing use of 'choice'. The nature of teaching and assessment have often been routinized and unreflective areas of practice that now require deconstruction and reconceptualization, if the benefits of enriched media use and peer interaction are to be realised. If the boundaries of contexts for teaching and learning are becoming more porous, what forms of teaching emerge, what new roles for supporting learning are being constructed, and what is their impact on learners and learning? In particular, do certain pedagogical practices encourage mobilisation and mediation more than others? With what effects, for teachers, learners and the quality of learning?

- How do we methodologically and theoretically conceptualise contexts for learning? What then constitutes a context for learning? What are the textual practices that constitute a context? The notion of community has become a favoured way of understanding the development of learning in different contexts. Communities of practice, discourse, place and focus communities, amongst others, have all been developed as a way of framing learning. For some, these framings provide a too bounded sense of context and do not capture the relational nature of learning. If learning is situated, how does one frame the notion of situation? Thus the notions of network and activity system have also been developed as a way of framing practice. The extent to which these are descriptive or explanatory metaphors remains open to question. How research is to be conducted with such understandings of learning has resulted in work adopting ethnographic, life history and narrative approaches.

Overarching these specific questions - and there are many more - are three broad one's which we wanted to address in the seminar series that provided the basis for this special issue:

1. What are the assumptions about learning and context underpinning pedagogical practices? 
2. What are the pedagogical implications of understanding learning and context in particular ways?

3. How can we best understand learning and context in order to mobilise learners' resources and relationships across domains?

Whether, in the process, this involves dropping the notion of context altogether in favour of, form instance, polycontextuality and activity systems or using the latter to provide a better understanding of learning and context remains to be seen.

It is such questions that the following articles attempt to engage with, whether exploring the question of learning and context in the classroom (Jewitt), the learning relationships in community-based college provision (Mayes and Crossan), the mobilizing of literacy practices from the everyday to the formal curriculum (Satchwell and Ivanic), the gendered learning of the school playground (Paechter), the mediations of different levels of context in the workplace (Unwin et al.), or the networked mediations in online learning (Thorpe at al.). Each article explores a specific pedagogical case and highlights some of the issues and illustrates some of the conceptual framings through which we can explore issues of learning and context. In the process of course, these articles have been mobilized from being papers presented at a seminar for a particular purpose into a different context of the academic article published in a referee journal. Each has had its own journey and translations in order to appear here, partly at least realized through the networking activity of we as editors.

The collection as a whole does not and is not intended to suggest ways of settling debates in this area. It is intended as a stimulus to further debate on a set of issues and questions which are implicit in the daily practices of pedagogy, but which are not always surfaced.

\section{Note}

The ideas explored in this article were rehearsed on a number of occasions in 2005. We would like to thank the many people, too many to record, who have engaged on the issues raised and the formulations put forward. The article is based upon work funded by the ESRC's Teaching and Learning Research Programme (ref: RES-13925-0174).

\section{References}

Barton, D. and Hamilton, M. (1998) Local literacies (London, Routledge).

Barton, D., Hamilton, M. and Ivanic, R. (eds) Situated literacies (London, Routledge).

Beach, K. (2003) Consequential transitions: a developmental view of knowledge propagation through social organisations, in T. Tuomi-Grohn and Y. Engestrom eds. Between work and school: new perspectives on transfer and boundary-crossing (London, Pergamon).

Bernstein, B. (1999) Vertical and horizontal discourse: an essay, British Journal of Sociology of Education, 20(2), 157-73.

Billett, S. (2002) Critiquing workplace learning discourses: participation and continuity at work, Studies in the Education of Adults, 34(1), 65-67.

Boreham, N., Samurcay, R. and Fischer, M. (eds) (2002) Work process knowledge (London, Routledge). 
Bowker, G. and Star, S. (2000) Sorting things out: classification and its consequences (Cambridge, Mass., MIT Press).

Chaiklin, S. and Lave, J. (eds) (1996) Understanding practice: perspectives on activity and context (Cambridge, Cambridge University Press).

Coffield, F. (2000) Introduction: the structure below the surface: reassessing the significance of informal learning, in F. Coffield (ed) The ecessity of informal learning (Bristol, Policy Press).

Colley, H., Hodkinson, P., Malcolm, J. (2003) Informality and formality in learning (London, LSDA).

Cunningham, S., Tapsall, S., Ryan, Y., Stedman, L., Bagdon, K. and Flew, T. (1997) New media and borderless education: a review of the convergence between global media networks and higher education provision (Canberra, Department of Employment, Education, Training and Youth Affairs).

Edwards, A. (2001) Researching pedagogy: a sociocultural agenda, Pedagogy, Culture, Society, 9(2), 161-86.

Edwards, R., Armstrong, P. and Miller, N. (2001) Include me out: critical readings of social exclusion, social inclusion and lifelong learning, International Journal of Lifelong Education, 20(5), 417-28.

Engestrom, Y., Miettinen, R. and Punamaki, R-L. (eds) (1999) Perspectives on activity theory (Cambridge, Cambridge University Press).

Eraut, M. (2000) Non-formal learning, implicit learning and tacit knowledge in professional work, in F. Coffield (ed) The necessity of informal learning (Bristol, Policy Press).

Eraut, M. (2004) 'Informal learning in the workplace', Studies in Continuing Education 26, 2: 247-74.

Field, J. (1996) Open learning and consumer culture, in P. Raggatt, R. Edwards and N. Small (eds) The learning society: trends and issues (London, Routledge).

Fox, S. (2000) Communities of practice, Foucault and actor-network theory, Journal of Management Studies, 37(6), 853-67.

Hughes, C. (2004) The supervisor's influence on workplace learning, Studies in Continuing Education, 26(2), 275-88.

Lankshear, C., Peters, M. and Knobel, M. (1996) Critical pedagogy and cyberspace, in H. Giroux, C. Lankshear, P. McLaren and M. Peters (eds) Counternarratives (London, Routledge).

Lave, J. (1996) The practice of learning, in S. Chaiklin and J. Lave (eds) (1996) Understanding practice: perspectives on activity and context (Cambridge, Cambridge University Press).

Lave, J. and Wenger, E. (1991) Situated learning, Cambridge: Cambridge University Press.

Lea, M. and Nicoll, K. (eds) (2002) Distributed Learning (London, Routledge).

Maybin, J. (2000) The New Literacy Studies: context, intertextuality and discourse, in D. Barton, M. Hamilton and R. Ivanic (eds) Situated literacies: reading and writing in context (London, Routledge).

Mayes, J.T, Dineen, F., McKendree, J., and Lee, J. (2001) Learning from watching others learn, in C.Steeples \& C. Jones (Eds) Networked learning: perspectives and issues (Springer, London).

Murphy, P. and Ivinson, G (2003) Pedagogy and cultural knowledge, special issue of Pedagogy, Culture and Society, 11(1).

Nespor, J. (1994) Knowledge in motion (London, Falmer). 
Nespor, J. (2003) Undergraduate curricula as networks and trajectories, in R. Edwards and R. Usher (eds) Space, curriculum and learning (Greenwich, IAP).

Oates, T. (1992) Core skills and transfer: aiming high, Educational Technology and Training International, 29(3)

Poell, R., Chivers, G., Van der Krogt, F and Wildemeersch, D. (2000) Learningnetwork theory, Management Learning, 31(1), 25-49.

Russell, D. and Yanez, A (2003) 'Big picture people rarely become historians': genre systems and the contradictions of general education, available at http://wac.colostate.edu/books/selves_societies/ (accessed 25 March 2004).

Star, S. L. (1989) The structure of ill-structured solutions: boundary objects and heterogeneous distributed problem solving, in L. Gasser and M. Huhns (eds) Distributed artificial intelligence, Vol. II (London, Pitman).

Stein, S., Isaacs, G. and Andrews, T. (2004) Incorporating authentic learning experiences within a university course, Studies in Higher Education, 29(2), 239-58.

Swales, J. (1998) Other floors, other voices: a textography of a small university building (Mahwah, NJ, Lawrence Earlbaum).

Tochon, F. (2000) When authentic experiences are 'enminded' into disciplinary genres: crossing biographic and situated knowledge, Learning and Instruction, 10, 331-59.

Tuomi-Grohn, T. and Engestrom, Y. (eds) (2003) Between work and school: new perspectives on transfer and boundary-crossing (London, Pergamon).

Tuomi-Grohn, T. and Engestrom, Y. (2003a) Conceptualising transfer: from standard notions to developmental notions, in T. Tuomi-Grohn and Y. Engestrom (eds) Between work and school: new perspectives on transfer and boundary-crossing (London, Pergamon).

Tuomi-Grohn, T., Engestrom, Y. and Young, M. (2003) From transfer to boundarycrossing between school and work as a tool for developing vocational education: an introduction, in T. Tuomi-Grohn and Y. Engestrom (eds) Between work and school: new perspectives on transfer and boundarycrossing (London, Pergamon).

Van Oers, B. (1998) From context to contextualizing, Learning and Instruction, 8(6), 473-88. 